\title{
O lugar do menor direito: fronteiras e exclusão social
}

\author{
The place of the smallest right: borders and social exclusion
}

\author{
Karine Cordazzo* \\ Gustavo Preussler ${ }^{* *}$
}

\section{Resumo}

\begin{abstract}
A ausência de amparo estatal nos municípios localizados na faixa de fronteira facilita e possibilita o processo de exclusão social. Em que pese a faixa de fronteira figurar como marco essencial para a integração regional bem como para a cooperação entre Estados, os próprios nacionais que nessas localidades se situam acabam por sofrer os drásticos impactos da exclusão social ocasionada pelo abandono estatal. Afinal, o interesse por essas localidades limita-se apenas ao âmbito econômico. Dessa forma, as injustiças sociais e materiais, conjugadas à ausência de intervenção estatal, transformam a região fronteiriça em um local completamente invisível. Por outro lado, a inovação trazida pela Lei de Migração possibilita um novo enfoque quanto ao denominado residente fronteiriço, reforçando, assim, a necessidade de valorizar a integração e o desenvolvimento das regiões fronteiriças, bem como de articular políticas públicas capazes de garantir efetivamente direitos básicos dos residentes fronteiriços.
\end{abstract}

Palavras-chave: Faixa de fronteira. Exclusão social. Direitos humanos.

\section{Abstract}

The absence of state support in the municipalities located in the border area facilitates and makes possible the process of social exclusion. Although the border area is an essential landmark for regional integration as well as cooperation between States, the very natives who live in these localities end up suffering the drastic impacts of social exclusion caused by the state's abandonment. After all, the interest in these localities is limited only to the economic sphere. In this way, social and material injustices, coupled with the absence of state intervention, transform the frontier region into a completely invisible place. On the other hand, the innovation brought by the Migration Law allows a new approach to the so-called border resident, thus reinforcing the need to value the integration and development of border regions, as well as to articulate public policies capable of effectively guaranteeing basic rights of border residents.

Keywords: Border band. Social exclusion. Human rights.

\section{Introdução}

O presente trabalho pretende demonstrar a necessidade de abordar a temática da ausência de amparo estatal nos municípios localizados na faixa de fronteira.

Apesar de o Brasil fazer fronteira com diversos países, a questão relativa ao desenvolvimento social das regiões fronteiriças não ganha sequer destaque na agenda política, nem com leis específicas, nem com políticas públicas que estimulem a superação das dificuldades existentes nessas localidades.

No entanto, em que pese a faixa de fronteira figurar como marco essencial para a integração regional, bem como para a cooperação entre estados, os próprios nacionais que naquela região se situam acabam

\footnotetext{
Mestranda em Fronteiras e Direitos Humanos pela Universidade Federal da Grande Dourados - UFGD (Bolsista CAPES). Especialista em Ciências Penais pela Universidade Anhanguera - UNIDERP. Grande Dourados-MS- Brasil. E-mail: karine.cordazzo@hotmail.com.

* Doutor em Direito pela Universidade do Estado do Rio de Janeiro. Mestre em Ciência Jurídica pela Universidade Estadual do Norte do Paraná. Especialista em Docência no Ensino Superior (UNIPAN). Professor Assistente Nível II de Direito Penal e Processo Penal. Professor Adjunto II da UFGD. Professor do Programa de Pós-graduação Stricto Sensu (Mestrado Multidisciplinar) em Fronteiras e Direitos Humanos. Atua especialmente na linha de pesquisa Sistema Penal e Direitos Humanos e é coordenador do Observatório de Ciências Criminais e Direitos Humanos. Grande Dourados-MS- Brasil. E-mail: gustavopreussler@ufgd.edu.br.
} 
por sofrer os drásticos impactos da exclusão social ocasionada pelo abandono estatal. Afinal, a grande maioria dos recursos canalizados para a faixa de fronteira não seriam, por consectário lógico, utilizados para fins sociais.

Demonstrar-se-á, de tal maneira, a patente necessidade de que o Estado volte sua atenção para sanar as desigualdades regionais existentes no Brasil, especialmente quando se trata da região fronteiriça, pois somente com atuação conjunta das diversas instâncias federais será possível alcançar esse objetivo.

Nesse contexto, a nova Lei de Migração traz à tona uma nova perspectiva quanto aos residentes fronteiriços e à própria região de fronteira, simbolizando a necessidade de que sejam implementadas políticas públicas voltadas para atender às necessidades específicas dessas localidades.

\section{A faixa de fronteira no Brasil}

O Brasil delimitou sua faixa de fronteira ${ }^{1}$ em cento e cinquenta quilômetros de largura ao longo das fronteiras terrestres, considerando-a fundamental para a defesa do território nacional. É importante destacar que as fronteiras são consideradas "faixas territoriais [...] que possuem uma complexa convergência de fatores culturais, econômicos, políticos e sociais. [...] são de extrema relevância, pois, representam o contato direito entre Estados". (MACHADO, 2017, p. 74).

De acordo com dados da Polícia Federal - órgão permanente, organizado e mantido pela União, e destinado a zelar pela faixa de fronteira -, o Brasil possui 16.886 quilômetros de fronteira seca, com Uruguai, Argentina, Paraguai, Bolívia, Colômbia, Peru, Venezuela, Guiana e Suriname (excetuam-se, na América do Sul, apenas Chile e Equador), sendo que muitas cidades brasileiras possuem importantes limites com cidades estrangeiras, a exemplo de Foz do Iguaçu (PR), Oiapoque (AP), Pacaraima (RR), Bonfim (RR), Brasiléia (AC), Corumbá (MS), Jaguarão (RS), Ponta Porã (MS), Santana do Livramento (RS) e Tabatinga (AM).

Esta "posição geográfica, de proximidade ao país vizinho, é um atributo que confere a essas aglomerações forte potencial de atuar como nódulos articuladores de redes locais, regionais, nacionais e transnacionais" (MACHADO, 2010, p. 66). Com efeito, é possível observar a mudança de uma antiga perspectiva do sentido de fronteira, estabelecida anteriormente como marco de separação, para agora ser entendia como um ambiente propício à cooperação. ${ }^{2}$

Nesse liame, Furtado (2011, p. 376) também esclarece que "essa faixa dever ser entendida não apenas como um marco que delimita o território nacional, mas sim, como uma região que possibilita e facilita a integração", pois, ao mesmo tempo em que separa os Estados, é também ponto de conexão e desenvolvimento.

Para Prado (2013, p. 19), a integração regional "surge a partir de duas questões básicas: a primeira remete à questão regional, ou seja, a uma denominada área geográfica [...]. A segunda remete à questão econômica, social, cultural e política entre os territórios". No entanto, apesar do processo de integração regional emergir como peça-chave nas relações internacionais, é nítida a predominância de fins puramente econômicos e comerciais. ${ }^{3}$

Lei $n^{\circ} 6.634$, de 2 de maio de 1979. "Art. $1^{\circ}$. É considerada área indispensável à Segurança Nacional a faixa interna de 150 Km (cento e cinquenta quilômetros) de largura, paralela à linha divisória terrestre do território nacional, que será designada como faixa de fronteira".

A preocupação em promover uma aproximação com os países vizinhos é uma política recente que inverte a lógica de "estar de costas" para os países que estão territorialmente próximos. No período geopolítico em que as fronteiras tinham enfoque de contenção, a preocupação com as infraestruturas de ligação com os países lindeiros era praticamente nula. Contudo, a inversão dessa lógica, no cenário contemporâneo, caracterizado por tendências de integração regional, torna-se estratégica a conexão física entre os dois países (DIETZ, 2008, p.18).

3 Prossegue Prado (2013, p. 43), "a evolução do processo de integração regional se desenha na construção de propostas conjuntas de viés econômico, financeiro, monetário, político e social”. Com efeito, tem-se que o processo de integração regional, de desenvolvimento das regiões da faixa de fronteira, não se consolida unicamente no âmbito econômico, pelo contrário; é necessário, acima e antes de mais nada, o alcance do bem-estar social das pessoas que lá vivem. 
Nesse sentido, chama-se a atenção ao fato de que a integração regional não consegue ser efetivada somente pelo fortalecimento econômico, pelo contrário. É necessário que os governos se aproximem e otimizem políticas públicas voltadas para as comunidades localizadas na região de fronteira. "Desta forma, o crescimento econômico estaria intimamente relacionado ao desenvolvimento social e ao fortalecimento político dos atores envolvidos" (FURTADO, 2011, p. 372), necessitando uma aproximação de ambas as partes para que a integração regional seja efetivamente alcançada.

Nesse contexto, é possível observar que a predominância de fins puramente econômicos na região fronteiriça destaca o processo discriminatório e excludente que lá se perpetua, e que teria como ponto de partida a própria conduta estatal. Negligentemente, o Estado lança à própria sorte o destino e a situação dos próprios nacionais que se encontram na faixa de fronteira.

Extrai-se, desse cenário, que os poucos recursos e esforços que são de fato canalizados para a faixa de fronteira dizem respeito única e exclusivamente para fins econômicos e comerciais, o que possibilita, por reflexo, a transformação daquela região em um verdadeiro reduto de pobreza e de marginalidade. Afinal, a criação e implementação de políticas sociais não passa de uma mera utopia.

\section{0 papel do Estado na tutela da região fronteiriça}

Assevera Carnelutti (2002, p. 66) que, "el Estado, tal cual hoy lo vemos, es um organismo inmenso. No hay probabelmente ninguma máquina física tan extensa y complicada". É nesse sentido, pois, que pode ser desvelada a ilusão acerca de um Estado direcionado ao alcance do bem-estar social.

Wolkmer (1990, p. 12) destaca que o Estado seria uma espécie de organização política "munida de coerção e de poder, que pela legitimidade da maioria, administra os amplos interesses e objetivos de todo social, sendo sua área de atuação delimitada a um determinado espaço físico". Deve, para tanto, executar a vontade da maioria dos indivíduos, ser independente e manter-se distante dos conflitos de classes, pois representa o interesse comum.

Essa visão falaciosa do Estado não se coaduna com a realidade pós-moderna. Em verdade, o Estado, além de revelar sua faceta elitista, aponta para um sistema de administração completamente centralizado, sobremaneira desvinculado dos anseios de sua população. ${ }^{4}$

Note-se, pois, que a ideia de um Estado centralizado vai na contramão da ideia erigida pelo federalismo. "A previsão constitucional de um sistema federal no Brasil já data mais de um século" (RAMOS, 2012, p. 27), optou-se, pois, com a queda do regime monárquico, não apenas por um regime republicano, mas também pela implementação de um Estado federado, formalmente instituído com a Constituição de 1891.

A proposta de um modelo federativo no Brasil, dentre outros objetivos, possuía a finalidade de reduzir os desequilíbrios regionais ${ }^{5}$ através da cooperação e a integração nacional, o que aparentava ser um sonho distante, mas possível. Em que pese essa louvável tentativa de uniformização das desigualdades regionais por meio da atuação conjunta das diversas instâncias federais, o Estado acabou por instituir uma política completamente distinta; comprometendo, por assim dizer, o próprio federalismo. Magalhães (2000, p. 15) afirma que "o nosso federalismo se encontra fortemente comprometido, assim como nossa democracia, por um governo federal altamente centralizador e autoritário, portanto, inconstitucional".

Nesse contexto, Barroso (2011, p. 27-28) adverte que em um Estado constitucional é imprescindível que existam limites ao poder e à atuação estatal. No que tange às limitações materiais, são consideradas

\footnotetext{
A decorrente composição arcaica, elitista e viciada de dominação, a que o Estado tem prestado conivência e indiscutível apoio, favorece a perpetuação de relações sociais assentada no clientelismo, no apadrinhamento, no nepotismo, no coronelismo, na ética da malandragem e da esperteza, e, na gama incontável de irregularidades e desvios no padrão cultural de comportamento do homem brasileiro (WOLKMER, 1990, p. 46).

5 No tocante às desigualdades regionais, a Constituição de 1988, em seus artigos $3^{\circ}$, III, que trata dos objetivos fundamentais da República Federativa do Brasil, e 170, VII, que enumera os princípios constitucionais da ordem econômica, considera imprescindível a redução das desigualdades regionais e sociais. Cabe também à União articular o desenvolvimento e a redução das desigualdades regionais, através da criação de regiões administrativas, incentivos e da ação de organismos regionais (artigo 43) (BERCOVICl, 2004, p. 63).
} 
"valores básicos e direitos fundamentais que hão de ser sempre preservados, como a dignidade da pessoa humana, a justiça, a solidariedade e os direitos à liberdade de religião, de expressão, de associação". Ocorre, no entanto, que tais limitações parecem, cada vez mais, situarem-se apenas no plano teórico. Afinal, dada a existência de um Estado socialmente negligente e centralizado - como o Brasil -, sequer se pode afirmar que princípios basilares, como o da dignidade da pessoa humana, ${ }^{6}$ realmente são efetivados.

Isto nos leva a crer que, ante a ausência de um Estado que priorize a solução das desigualdades regionais, torna-se inviável a cooperação da União com os demais entes federados para a implementação de políticas públicas, sobretudo aquelas voltadas para regiões marginais, como a faixa de fronteira.

Além do mais, a criação e o desenvolvimento de políticas públicas voltadas ao bem-estar da população necessita, prioristicamente, de colaboração do Estado, uma vez que a insuficiência econômica dos municípios para atuarem autonomamente ao repasse estatal é praticamente impossível.

Não se pode olvidar, portanto, que é papel do Estado, personificado na figura da União, a tutela de assuntos pertinentes às regiões fronteiriças, uma vez que a própria Constituição Federal estabelece como bem da União "as terras devolutas indispensáveis à defesa das fronteiras".

Destarte, uma vez existente a previsão legal acerca da necessidade de tutelar as regiões fronteiriças, tal mandamento não pode ser ignorado. Konrad Hesse brilhantemente leciona acerca da eficácia normativa da constituição e da necessidade de que suas disposições sejam cumpridas. "La Constitución se compone de normas. Estas contienen requerimientos dirigidos a la conducta humana, [...]; las normas no son más que letra muerta sin eficacia alguna cuando el contenido de tales requerimientos no se incorpora a la conducta humana" (HESSE, 1983, p. 26). ${ }^{7}$

O objetivo almejado é claro, "a execução uniforme e adequada de serviços públicos equivalentes em toda a Federação, de acordo com os princípios da solidariedade e da igualação das condições sociais de vida" (BERCOVICl, 2004, p. 59). Porém, a realidade política e social enfrentada na faixa de fronteira parece cada vez menos ir ao encontro desse objetivo.

Pontua-se que essa concepção de marginalidade das zonas fronteiriças remonta à ideia de centralismo político. "O centralismo político significa entre nós prevalência do poder econômico e, por conseguinte, subordinação das regiões economicamente mais débeis aos interesses daqueles que assumiram a vanguarda do processo de industrialização". (FURTADO, 1999, p. 54).

É o que ocorre com a região de fronteira. O Estado destina a maioria de seus recursos e de seus esforços às questões dos grandes centros, enquanto as regiões marginais, nitidamente impotentes perante as regiões mais desenvolvidas, ficam sujeitas a uma atenção subsidiária por parte do Estado.

Uma possível solução estaria vinculada à ideia de integração regional, ou seja, quando as cidades marginais - a exemplo dos municípios localizados na faixa de fronteira - têm suas reivindicações descoladas da atenção central do Estado. É primordial que se construam laços de proximidade com o país vizinho, possibilitando, de tal sorte, que essa situação de completo abandono seja atenuada.

Com efeito, é preciso "fazer da zona de fronteira o 'centro' com seus próprios autorreferentes em vez de margem do estado nacional". (MACHADO, 2010, p. 68). É preciso lembrar que o Estado se inicia a partir de suas fronteiras e é por meio que delas que é possível a concretização da tão aclamada integração regional, não devendo - dada sua relevância - tornar-se invisível.

\footnotetext{
O princípio da dignidade humana identifica um espaço de integridade a ser assegurado a todas as pessoas por sua só existência no mundo. É um respeito à criação, independente da crença que se professe quanto à sua origem. A dignidade relaciona-se tanto com a liberdade e valores do espírito quanto com as condições materiais de subsistência. O desrespeito a esse princípio terá sido um dos estigmas do século que se encerrou e a luta por sua afirmação, um símbolo do novo tempo. Ele representa a superação da intolerância, da discriminação, da exclusão social, da violência, da incapacidade de aceitar o outro, o diferente, na plenitude de sua liberdade de ser, pensar e criar (BARROSO, 2011, p. 274).

Complementa Hesse (1983, p. 28), "De otra parte, la fuerza normativa de la Constitución se halla condicionada por la voluntad constante de los implicados en el proceso constitucional de realizar los contenidos de la Constitución. Puesto que la Constitución como todo orden jurídico precisa de su actualización por medido de la actividad humana, su fuerza normadora depende de la disposición para considerar como vinculantes sus contenidos y de la resolución de realizar estos contenidos incluso frente a resistencias; ello tanto más cuanto que la actualización de la Constitución no puede ser apoyada y garantizada en la misma medida que la actualización de otro derecho por los poderes estatales, los cuales no son constituidos sino a través de esta actualización".
} 
Nesse contexto, é inconcebível afirmar que o Estado brasileiro possa ser detentor de uma faixa de fronteira forte, que garanta a segurança nacional, que seja sinônimo de integração regional, mas, que ao mesmo tempo, ignore as demandas específicas dessa região, não despendendo tempo, nem recursos e, mais do que isso, permitindo que condições de vida precárias e até mesmo subumanas para os residentes fronteiriços sejam perpetuadas.

\section{A faixa de fronteira como fator de exclusão social}

A consolidação dos direitos humanos na segunda metade do século XX e a eficácia normativa conferida aos mesmos pelas constituições democráticas contribuíram para que os direitos humanos deixassem de representar meras teorias para ganhar concretude; protegendo, assim, todo e qualquer indivíduo que, conforme Piovesan (2007, p. 118), "representam o referencial ético a orientar a ordem internacional contemporânea".

É certo que "os direitos humanos só puderam florescer quando as pessoas aprenderam a pensar nos outros como seus iguais, como seus semelhantes em algum modo fundamental". (HUNT, 2009, p. 58). Com isso, a ideia de preservação das diferenças naturais e culturais como meio de fortalecer a humanidade ganhou amplitude; admitindo-se, para tanto, que a humanidade pode sim enfraquecer "com a instituição de desigualdades sociais, isto é, de situações de dominação de uns sobre outros, fundada na pretensa superioridade universal de um sexo, de uma raça ou de uma cultura" (COMPARATO, 2004, p. 427).

Atrelada a essa ideia, surge a necessidade de uma concepção contra-hegemônica ${ }^{8}$ de direitos humanos, orientada tanto pelo direito à igualdade como pelo reconhecimento da diferença. Como bem assevera Santos (2011, p. 13), "cada vez mais e de forma mais insidiosa, temos convivido no interior de Estados democráticos clivados por sociedades fascizantes em que os índices de desenvolvimento são acompanhados por indicadores gritantes de desigualdade, exclusão social [...]".

Notadamente, uma das grandes consequências desse processo de exclusão reflete peremptoriamente no isolamento de determinados indivíduos, ou grupos de pessoas, a exemplo dos residentes fronteiriços. A situação marginal em que vivem simboliza não apenas o limite geográfico da faixa de fronteira, mas também a invisibilidade perante a atuação estatal, dada a relevância predominante dos grandes centros, da preferência cosmopolita do Estado. "A separação espacial que produz um confinamento forçado tem sido ao longo dos séculos uma forma quase visceral e instintiva de reagir a toda diferença e particularmente à diferença que não podia ser acomodada nem se desejava acomodar [...]" (BAUMAN, 1999, p. 114).

Fica claro que a região fronteiriça facilita e possibilita grandemente o processo de exclusão social. De um lado, por ser uma região geograficamente marginalizada - por conseguinte, abandonada pelo próprio poder estatal - e, de outro, por se ponto de contato entre as mais variadas culturas - por grupos notadamente minoritários, como indígenas, brasiguaios, etc., o que, per si, já garante que essa região se torne lócus de exclusão.

Quanto aos grupos notadamente minoritários, Seguin (2002, p. 12) aponta um aspecto interessante: "é que com certa frequência eles não tem sequer a noção que estão sendo vítimas de discriminação ou que seus direitos estão sendo desrespeitados: eles sequer sabem que têm direitos". Isto se encaixa perfeitamente na situação dos residentes fronteiriços, pois, aparentemente, o mero fato de residir na faixa de fronteira têm se tornado sinônimo de discriminação, solapamento de direitos básicos e fator de exclusão social.

Nota-se, dessa forma, que a delimitação territorial da faixa de fronteira ultrapassa os limites geográficos e penetra a ordem social, favorecendo a discriminação entre "nós", os próprios nacionais, e eles, os situados à margem do território nacional e da própria sociedade. Inegavelmente, são os residentes fronteiriços

Nesse sentido, "é necessária uma concepção contra-hegemônica de direitos humanos, que permita a coexistência entre direitos individuais e direitos coletivos, que se paute tanto pelo direito à igualdade como pelo direito ao reconhecimento da diferença, e, sobretudo, que não se autocontemple em proclamações, tão exaltantes quanto vazias, de direitos fundamentais, que, normalmente, de pouco servem àqueles que vivem na margem da sobrevivência em contato permanente com a desnutrição e a violência. Uma concepção contra-hegemônica dos direitos humanos tem de enfrentar a situação dos desempregados e dos trabalhadores precários, dos camponeses sem-terra, dos indígenas espoliados, das vítimas de despejo, das mulheres violentadas, das crianças e adolescentes abandonados, dos pensionistas pobres [...]". (SANTOS, 2011, p. 103). 
que figuram como protagonistas nesse processo de exclusão, tornando-se os principais alvos do descaso praticado, ou melhor, da negligência perpetuada pelo próprio Estado.

A partir desse cenário de completo abandono é possível constatar que a região fronteiriça convive lado a lado com uma triste realidade, a constante pobreza. ${ }^{9} \mathrm{~A}$ pobreza, isoladamente falando, já facilita por demasiado o processo de exclusão, acrescente-se aí a situação de ser pobre em uma região fronteiriça, região completamente negligenciada e abandonada pelo poder estatal. Ora, as condições não poderiam ser mais favoráveis para a perpetração de uma exclusão social ainda mais radical.

No que tange ao combate à pobreza, Demo (1996, p. 7) estabelece três linhas principais a serem alcançadas: a "[...] assistência social, como direito à sobrevivência, inclusão econômica, por necessidade de autossustentação, e inclusão política, por conta da emancipação histórica". No entanto, no estágio atual de globalização, "nenhum governo, isolado ou mesmo em grupo, consegue equilibrar as contas. Sem isso, a capacidade de o 'Estado Social' continuar com sua prática de erradicar efetivamente a pobreza no plano doméstico é inconcebível” (BAUMAN, 2013, p. 37).

É importante lembrar que, conforme leciona Barroso (2011, p. 92), ao estabelecer uma noção de interesse público no direito contemporâneo, a promoção do bem-estar social é a razão de ser do Estado. "O interesse público primário é a razão de ser do estado e sintetiza-se nos fins que cabe a ele promover: justiça, segurança e bem-estar social". Portanto, a cidadania social deve entendida não como uma questão subsidiária, mas como uma questão tão importante quanto à cidadania legal e política.

Destaca-se também que, além da erradicação da pobreza e da redução de desigualdades sociais e regionais, a promoção do bem-estar social constitui um dos objetivos fundamentais da República Federativa do Brasil, consoante dicção do artigo $3^{\circ}$ da Constituição Federal. Infere-se desse dispositivo "quão acentuada é a preocupação da Constituição em assegurar os valores da dignidade e do bem-estar da pessoa humana, como imperativo de justiça social". (PIOVESAN, 2007, p. 27).

Embora possam ser considerados legítimos, tais objetivos erigidos no diploma constitucional, atualmente a lógica do mercado destrói a lógica do bem-estar social. O avanço desordenado do processo de globalização e a busca incessante pelo capital fazem com que o Estado priorize demandas econômicas e deixe questões sociais básicas a um plano completamente intangível. ${ }^{10}$

Neste contexto, aduz Celso Furtado (1999, p. 13), ao tratar da formação econômica do Brasil, que o país "acumulou historicamente um considerável atraso em investimento no fator humano [...]. A miséria de grande parte do povo brasileiro é a contrapartida do hiperconsumo praticado por uma pequena minoria em termos relativos". Complementa o autor, que "[...] a lógica desse processo sofreu profundas mutações à medida que a ideologia do bem-estar coletivo foi perdendo força, suplantada pela racionalidade mercantil." (FURTADO, 1999, p. 13).

A exclusão social, portanto, decorre de um verdadeiro processo bulímico que inclui, e, posteriormente, exclui os membros da sociedade. "[...] A ordem social do mundo industrial avançado é uma ordem que engole seus membros. Ela consome e assimila culturalmente massas de pessoas através da educação, da mídia e da participação no mercado". (YOUNG, 2002, p. 125). Com efeito, as pessoas são instadas a participar do sistema capitalista, de consumir de maneira desenfreada. São instigadas pela busca do tênis

9 Estamos habituados a ver pobreza como carência material, no plano do ter: é pobre quem não tem renda, emprego, habitação, alimentos etc. Essa dimensão é crucial e não poderia, em momento algum, ser secundarizada. Mas a dinâmica da pobreza não se restringe à esfera material do ter. Avança na esfera do ser e, possivelmente, alcança aí intensidades ainda mais comprometedoras. Mais drástico do que não ter mínimos materiais para sobreviver é não ser nada na vida (DEMO, 2006, p. 25-26).

10 Nesse sentido, Sen (2010, p. 375) destaca: "Embora a prosperidade econômica ajude as pessoas a ter opções mais amplas e a levar uma vida mais gratificante, o mesmo se pode dizer sobre educação, melhores cuidados com a saúde, melhores serviços médicos e outros fatores que influenciam causalmente as liberdades efetivas que as pessoas realmente desfrutam. Esses 'desenvolvimentos sociais' têm de ser considerados diretamente 'desenvolvimentistas', pois nos ajudam a ter uma vida mais longa, mais livre e mais proveitosa, juntamente com o papel que desempenham no aumento da produtividade, do crescimento econômico ou das rendas individuais. O uso do conceito de 'capital humano'- que se encontra apenas em parte do quadro (uma parte importante, relacionada à ampliação do cômputo dos 'recursos produtivos') - é com certeza uma iniciativa enriquecedora. Mas necessita realmente de suplementação. Pois os seres humanos não são meramente meios de produção, mas também a finalidade de todo o processo". 
de marca, dos carros de luxo, das roupas de grife, mas, diante da impossibilidade de se inserirem neste círculo vicioso, são rotuladas, excluídas e, por conseguinte, estigmatizadas. Notadamente, a pobreza é consequência inevitável de um sistema capitalista bem-sucedido.

Tudo isso nos leva a crer na necessidade de que sejam implementadas políticas públicas que alcancem os que estão na margem da sociedade, que fomentem a distribuição das recompensas baseadas no mérito de cada um, extirpando de vez com a prática delével da alocação da riqueza nas mãos de uma minoria detentora do poder. "Através da abertura da esfera de trabalho a todos, da restrição à riqueza herdada e da garantia de que a remuneração reflita o mérito" (YOUNG, 2002, p. 274), é possível iniciar uma transformação, rompendo de vez com o paradigma da exclusão social, especialmente em regiões ainda mais esquecidas como a da faixa de fronteira.

\section{Do residente fronteiriço}

A Lei no 13.445, de 24 de maio de 2017, institui a denominada Lei de Migração, que tem como finalidade regular o ingresso e a permanência de estrangeiros no Brasil, seja de forma temporária (emissão de vistos), seja na modalidade definitiva (requisitos para naturalização), definir demais regras sobre impedimento de entrada ou exclusão dos estrangeiros, e ainda estabelecer regras inovadoras com relação à faixa de fronteira.

Nessa linha, busca a lei definir as diretrizes da política migratória brasileira, facilita o ingresso e permanência do estrangeiro em solo nacional, e amplia o rol de proteção aos indivíduos em situação de risco humanitário, como refugiados e apátridas, bem como ao denominado residente fronteiriço.

De acordo com o art. $1^{\circ}, \S 1^{\circ}$, IV da Lei de Migração, considera-se residente fronteiriço "a pessoa nacional de país limítrofe ou apátrida que conserva a sua residência habitual em município fronteiriço de país vizinho". Em seguida, a recente lei trata, nos art. 23 a $25,{ }^{11}$ das normas aplicáveis ao indivíduo nessa condição, inovando consideravelmente na tutela daqueles que vivem, muitas vezes, às margens de dois Estados soberanos.

A preocupação do legislador é justamente conferir tratamento jurídico ao intercâmbio cultural existentes nas regiões de fronteira, caracterizadas historicamente como ponto de convergência entre culturas, e fundamental para o deslocamento de indivíduos, o comércio exterior e o desenvolvimento de boas relações entre os Estados.

O Brasil possui alguns tratados que regulam as relações privadas entre residentes de cidades fronteiriças, a exemplo do Decreto $n^{\circ}$ 6.737, de 12 de janeiro de 2009, que promulga o Acordo entre o Governo da República Federativa do Brasil e o Governo da República da Bolívia para Permissão de Residência, Estudo e Trabalho a Nacionais Fronteiriços Brasileiros e Bolivianos, celebrado em Santa Cruz da Serra, em 8 de julho de 2004. No anexo do texto do Tratado estão definidas as localidades abrangidas: a) Brasiléia a Cobija, b) Guajará-Mirim (MT) a Guayeramirim, Cáceres (MT) a San Matías e d) Corumbá (MS) a Puerto Suarez.

Entretanto, por se tratar de uma autorização para realização de atos civis fora do local de domicílio do estrangeiro fronteiriço, o documento que autorizar a realização dos atos indicará especificamente a região na qual o estrangeiro gozará do status de residente fronteiriço, evitando a desvirtuação da autorização para uma espécie de "visto facilitado", conforme define o art. 24.

Do mesmo modo, por não se tratar de um direito de caráter absoluto, a autorização do residente fronteiriço poderá ser cancelada em caso de fraude nos documentos concessórios, em caso de obtenção

11 "Art. 23. A fim de facilitar a sua livre circulação, poderá ser concedida ao residente fronteiriço, mediante requerimento, autorização para a realização de atos da vida civil. Parágrafo único. Condições específicas poderão ser estabelecidas em regulamento ou tratado. Art. 24. A autorização referida no caput do art. 23 indicará o Município fronteiriço no qual o residente estará autorizado a exercer os direitos a ele atribuídos por esta Lei. $\S 1^{\circ} \mathrm{O}$ residente fronteiriço detentor da autorização gozará das garantias e dos direitos assegurados pelo regime geral de migração desta Lei, conforme especificado em regulamento. $\S 2^{\circ} \mathrm{O}$ espaço geográfico de abrangência e de validade da autorização será especificado no documento de residente fronteiriço. Art. 25. O documento de residente fronteiriço será cancelado, a qualquer tempo, se o titular: I - tiver fraudado documento ou utilizado documento falso para obtê-lo; II - obtiver outra condição migratória; III - sofrer condenação penal; ou IV - exercer direito fora dos limites previstos na autorização". 
de outra condição migratória mais abrangente, de condenação ou ainda de exercício irregular dos direitos a ele conferidos, preservando a soberania do Estado brasileiro no que se refere à admissão de estrangeiros.

Merece igual destaque o art. 112 da referida lei, que insere no ordenamento a possibilidade de utilização da língua fronteiriça nas repartições públicas das regiões limítrofes. Nos termos do mencionado dispositivo: "As autoridades brasileiras serão tolerantes quanto ao uso do idioma do residente fronteiriço e do imigrante quando eles se dirigirem a órgãos ou repartições públicas para reclamar ou reivindicar os direitos decorrentes desta Lei".

Com relação à tolerância das autoridades brasileiras quanto ao idioma dos residentes fronteiriços nas repartições públicas, observa-se louvável esforço do legislador quanto à necessidade de adequação da norma às especificidades locais. Ainda assim, entendemos se tratar de norma meramente declaratória, pois a generalidade do conceito de 'tolerantes' dificulta a delimitação do agir das autoridades públicas em tais situações.

Poucos são os exemplos de respeito ao residente fronteiriço pelo Poder Público, o que contribui para a marginalização social decorrente das barreiras impostas ao acesso dos serviços públicas nessas regiões.

Como exemplo de adoção de medida de inclusão de povos fronteiriços, o município de Tacuru, situado no sul do estado de Mato Grosso do Sul, adotou em 2010, mediante lei municipal, o idioma guarani nas escolas da rede pública de ensino, permitindo o acesso tanto dos indígenas que circulam entre Brasil e Paraguai quanto dos paraguaios que residem e trabalham na região e buscam, no Brasil, acesso a direitos sociais como saúde e educação. Desse modo, os fronteiriços contam com essa importante medida de valorização do guarani e suas variedades, como o kaiowá, o ñandeva e o mbya.

\section{Conclusão}

Como ponto intercessão, a faixa de fronteira deixou de simbolizar apenas uma separação entre Estados soberanos para se transformar em ponto estratégico na cooperação e integração regional.

Ocorre, no entanto, que os poucos recursos e esforços destinados pelo Estado para o desenvolvimento da região fronteiriça dizem respeito única e exclusivamente a fins meramente econômicos, o que acarreta, reflexamente, na transformação da faixa de fronteira em uma região completamente abandonada pelo Estado.

Essa concepção de marginalidade das zonas fronteiriças remonta à ideia de centralismo político. Afinal, há nítida prevalência do poder econômico e, por conseguinte, subordinação das regiões economicamente mais débeis aos interesses daquelas mais desenvolvidas.

O avanço desordenado do processo de globalização e a busca incessante pelo capital fazem com que o Estado priorize demandas econômicas, deixando questões sociais a um plano completamente intangível. Assim, a delimitação territorial da faixa de fronteira ultrapassa os limites meramente geográficos e penetra a ordem social, favorecendo o processo de discriminação, em que os situados à margem do território nacional se tornam também indivíduos marginalizados perante a própria sociedade. Inegavelmente, são os residentes fronteiriços que figuram como protagonistas nesse processo de exclusão, tornando-se os principais alvos do descaso praticado pelo Estado.

Isto nos leva a crer na necessidade de que o Estado atue não apenas nos grandes centros, mas também nas regiões marginais do território nacional, a exemplo da região fronteiriça no Brasil. Que o Estado seja proativo e não reativo, que desenvolva políticas públicas que atendam às demandas específicas dos municípios localizados na faixa de fronteira, que atue no combate à pobreza, que fomente a criação de empregos, que promova a igualdade material. É preciso, pois, que a faixa de fronteira deixe de ser considera como um local marginalizado do território nacional. A Lei de Migração surge como uma luz no fim do túnel, demonstrando a necessidade de valorização da região fronteiriça e dos próprios nacionais que lá vivem. 


\section{Referências}

BARROSO, Luis Roberto. Curso de direito constitucional contemporâneo: os conceitos fundamentais e a construção de um novo modelo. 3. ed. São Paulo: Saraiva, 2011.

BAUMAN, Zygmunt. Danos colaterais: desigualdades sociais numa era global. Tradução de Carlos Alberto Medeiros. Rio de Janeiro: Zahar, 2013.

BAUMAN, Zygmunt. Globalização: as consequências humanas. Tradução de Marcus Penchel. Rio de Janeiro: Zahar, 1999.

BERCOVICI, Gilberto. Dilemas do estado federal brasileiro. Porto Alegre: Livraria do Advogado, 2004.

BRASIL. Decreto n 6.737, de 12 de janeiro de 2009. Promulga o Acordo entre o Governo da República Federativa do Brasil e o Governo da República da Bolívia para Permissão de Residência, Estudo e Trabalho a Nacionais Fronteiriços Brasileiros e Bolivianos. Disponível em: <http://www.planalto.gov.br/ ccivil_03/_ato2007-2010/2009/decreto/d6737.htm>. Acesso em: 02 fev. 2018.

BRASIL. Lei no 13.445, de 24 de maio de 2017. Institui a Lei de Migração. Disponível em: <http://www. planalto.gov.br/ccivil_03/_ato2015-2018/2017/lei/L13445.htm>. Acesso em: 2 fev. 2018.

CARNELUTTI, Francesco. Cómo nace el derecho. Traducción Santiago Sentis Melendo; Marino Ayerra Redí. Bogotá: Temis, 2002.

COMPARATO, Fábio Konder. A afirmação histórica dos direitos humanos. 3. ed. rev. e ampl. São Paulo: Saraiva, 2004.

DEMO, Pedro. Combate à pobreza. Campinas: Autores Associados, 1996.

DEMO, Pedro. Pobreza política: a pobreza mais intensa da pobreza brasileira. Campinas: Armazém do Ipê, 2006.

DIETZ, Circe Inês. Cenários contemporâneos da fronteira Brasil-Argentina: infra-estruturas estratégicas e o papel dos atores no processo de cooperação/integração transfronteiriça. 2008. Dissertação (Mestrado em Geociências) - Universidade Federal do Rio Grande do Sul, Instituto de Geociências, Porto Alegre, 2008.

FURTADO, Celso. O longo amanhecer: reflexões sobre a formação econômica do Brasil. Rio de Janeiro: Paz e Terra, 1999.

FURTADO, Renata. As fronteiras no âmbito do Mercosul: apontamentos sobre a formação da agenda política de integração fronteiriça. Universitas Relações Internacionais, Brasília, v. 9, n. 1, p. 371-381, jan./jun. 2011.

HESSE, Konrad. Escritos de derecho constitucional. Madrid: Centro de Estudios Constitucionales, 1983.

MACHADO, Fernando. Direito internacional. Bauru: Spessotto, 2017.

MACHADO, Lia Osório. Cidades na fronteira internacional: conceitos e tipologia. In: NUÑES, Angel; PADOIN, Maria M.; OLIVEIRA, Tito Carlos Machado de. Dilemas e diálogos platinos. Dourados: UFGD, 2010. p. 59-72.

MAGALHAES, José Luiz Quadros de. Pacto federativo. Belo Horizonte: Mandamentos, 2000.

OLIVEIRA, Tito Carlos Machado de. Tipologia das relações fronteiriças: elementos para o debate teóricoprático. In: OLIVEIRA, Tito Carlos Machado de (Org.). Território sem limites: estudos sobre fronteira. Campo Grande: UFMS, 2005. p. 377-408.

PIOVESAN, Flávia. Direitos humanos e o direito constitucional internacional. 8. ed. rev. ampl. e atual. São Paulo: Saraiva, 2007.

PRADO, Henrique Sartori de Almeida. Inserção dos atores subnacionais no processo de integração regional: o caso do Mercosul. Dourados: UFGD, 2013. 
RAMOS, Paulo Roberto Barbosa. Federalismo e descentralização territorial em perspectiva comparada: os sistemas do Brasil e da Espanha. Porto Alegre: Sergio Antonio Fabris, 2012.

SANTOS, Boaventura de Sousa. Para uma revolução democrática da justiça. 3. ed. São Paulo: Cortez, 2011.

SEGUIN, Elida. Minorias e grupos vulneráveis: uma abordagem jurídica. Rio de Janeiro: Forense, 2002.

SEN, Amartya. Desenvolvimento como liberdade. Tradução de Laura Teixeira Motta; revisão técnica de Ricardo Doninelli Mendes. São Paulo: Companhia das Letras, 2010.

WOLKMER, A. C. Elementos para uma crítica do Estado. Porto Alegre: Sergio Antonio Fabris, 1990.

YOUNG, Jock. A sociedade excludente: exclusão social, criminalidade e diferença na modernidade recente. Tradução de Renato Aguiar. Rio de Janeiro: Revan; Instituto Carioca de Criminologia, 2002. (Pensamento criminológico; 7).

Recebido em: 02/02/2018

Aprovado em: 02/04/2018 